Artigo / Article

\title{
Anemia hemolítica auto-imune e outras manifestações imunes da leucemia linfocítica crônica
}

\author{
Autoimmune hemolytic anemia and other autoimmune diseases related to chronic lymphocytic \\ leukemia
}

José O. Bordin

\begin{abstract}
A leucemia linfocítica crônica (LLC) é freqüentemente associada a manifestações auto-imunes principalmente relacionadas às células do sistema hematopoético causando anemia hemolitica auto-imune (AHAI), púrpura trombocitopênica imune (PTI), aplasia pura de série vermelha (APSV), e neutropenia imune. A LLC é diagnosticada em até $15 \%$ dos pacientes com AHAI, e em cerca de 50\% dos pacientes com AHAI secundária a doença maligna. A PTI ocorre em 2\%, e a APSV em 1\% dos pacientes com LLC. Prednisona é o tratamento inicial de escolha para a citopenia imune associada à $L L C$. Para cerca de $60 \%$ dos pacientes que apresentam recidiva da manifestação auto-imune tem sido utilizada esplenectomia, imunoglobulina endovenosa, ou ciclosporina. Embora as evidências sobre fisiopatologia sejam limitadas, os mecanismos fisiopatológicos da auto-imunidade na LLC estão relacionados à atividade dos linfócitos B leucêmicos que atuam como células apresentadoras de antígeno aberrantes, e são eficientes em processar e apresentar proteinas da membrana de hemácias e de plaquetas às células TH auto-reativas. Linfócitos TH especificos para certos auto-antígenos podem escapar de mecanismos de controle de auto-tolerância, $e$, se ativados, podem causar doença auto-imune. O diagnóstico de AHAI contraindica o uso de fludarabina em pacientes com LLC, pois esse análogo da purina tem sido associado ao desenvolvimento de AHAI grave e fatal, com risco consideravelmente mais alto para pacientes mais imunossuprimidos devido a vários tratamentos anteriores. Rev. bras. hematol. hemoter. 2005;27(4):257-262.
\end{abstract}

Palavras-chave: Leucemia linfocítica crônica; anemia hemolítica auto-imune; transfusão de sangue; púrpura trombocitopênica; aplasia pura de série vermelha.

\section{Introdução}

A primeira descrição que a leucemia linfocítica crônica (LLC) pode ser associada à doença auto-imune ocorreu, provavelmente, em 1951, quando Berlin descreveu síndrome hemolítica em pacientes com LLC. ${ }^{1}$ As manifestações de auto-imunidade na LLC são predominantemente dirigidas contra células do sistema hematopoético ocasionando anemia hemolítica auto-imune (AHAI), púrpura trombocitopênica imune (PTI), aplasia pura de série ver- melha (APSV), e neutropenia imune. Além disso, têm sido relatadas associações da LLC com doenças auto-imunes não hematológicas, tais como síndrome nefrótica com glomerulonefrite, angioedema adquirido, pênfigo bolhoso, lupus eritematoso sistêmico, síndrome de Sjögren, doença de Graves, artrite reumatóide, retocolite ulcerativa, e vasculite alérgica, entre outras. ${ }^{2}$

$\mathrm{O}$ artigo de revisão aqui apresentado aborda os principais estudos da literatura sobre doenças auto-imunes em LLC; analisa as principais teorias fisiopatológicas para este

Professor titular da Disciplina de Hematologia e Hemoterapia da Universidade Federal de São Paulo.

Correspondência para: José Orlando Bordin

Universidade Federal de São Paulo - Disciplina de Hematologia e Hemoterapia

Rua Botucatu, 740

04023-902 - São Paulo - SP

Tel.: (11)5579-1550 - Fax: (11)5571-8806

E-mail:jobordin@hemato.epm.br 
fenômeno e descreve as estratégias de tratamento adotadas, atualmente, para o controle clínico dessas manifestações.

\section{Anemia hemolítica auto-imune}

A AHAI a quente é mais comum em pacientes com LLC do que na população geral, e a LLC é a causa mais comum de AHAI. ${ }^{2}$ Em cerca de $50 \%$ dos pacientes com AHAI não se encontra a causa (AHAI primária ou idiopática), ao passo que a LLC é diagnosticada em $15 \%$ dos pacientes com AHAI, e em cerca de $50 \%$ dos pacientes com AHAI secundária a doença maligna, representando cerca de duas vezes mais casos associados à LLC que associados com lupus eritematoso sistêmico, que é a segunda doença mais comumente associada à AHIA. ${ }^{3}$ Entretanto, observase na literatura uma disparidade quanto à prevalência de positividade do teste da antiglobulina direto (TAD, teste de Coombs direto) e de casos de AHAI em pacientes com LLC nos diferentes estudos, provavelmente devido à inclusão de pacientes em diferentes estádios de progressão da doença. Assim, o TAD foi positivo em 1,8\% dos pacientes incluídos no Grupo Cooperativo Francês de LLC, mas AHAI foi observada em 2,9\% dos pacientes em estádio A, 10,5\% em estádio B ou C, e 18,2\% em estádio A com progressão. ${ }^{4}$ De modo geral, considera-se que a AHAI ocorre na LLC com uma freqüência oito vezes maior que em linfomas nãoHodgkin, e duas a três vezes mais que na doença de Hodgkin., 2,5

\section{Púrpura trombocitopênica imune}

A prevalência de PTI em LLC é ao redor de $2 \%{ }^{4,5} \mathrm{O}$ diagnóstico de PTI em LLC é de exclusão e depende da presença de plaquetopenia isolada com aumento do volume plaquetário médio, e normoplasia ou hiperplasia megacariocítica na medula óssea, uma vez que os testes para deteç̧ão de anticorpos antiplaquetários ainda são relativamente insatisfatórios.

O fato de que a PTI possa ocorrer associada à AHAI (Síndrome de Evans) na LLC reforça a hipótese de que a plaquetopenia nesses casos tenha uma base auto-imune. Aproximadamente $30 \%$ dos pacientes com PTI e LLC apresentam TAD positivo. ${ }^{6}$

\section{Neutropenia auto-imune}

A neutropenia pode ocorrer em LLC devido à infiltração da medula óssea, à ação tóxica do tratamento ou, possivelmente, à auto-imunidade. Ainda não há dados convincentes na literatura sobre prevalência de neutropenia auto-imune em LLC, e a participação de anticorpos antineutrófilos nessa situação clínica precisa ser melhor avaliada. ${ }^{2}$

\section{Aplasia pura de Série Vermelha}

Assim como a neutropenia imune, a APSV é uma complicação relativamente rara na LLC, sendo estimado que ocorra em $1 \%$ dos pacientes. O diagnóstico deve ser lembrado quando ocorre anemia normocítica e normocrômica profunda, reticulocitopenia, e aplasia da série eritroblástica na medula óssea. ${ }^{2}$ A dosagem de desidrogenase láctica e bilirrubina indireta são normais.

\section{Manifestações auto-imunes não hematológicas}

Em uma população de indivíduos idosos é mais comum o encontro de auto-anticorpos com especificidade tissular variável, e a prevalência geral de auto-anticorpos em pacientes com LLC é similar àquela observada em indivíduos controles pareados por idade. Alguns estudos com séries de pacientes com LLC descrevem a associação de LLC com artrite reumatóde, cirrose criptogênica, vasculite, fibrose pulmonar, poliomiosite, miastenia gravis, tireodite de Hashimoto, espondilite anquilosante, doença de Graves, e irite, entre outras. ${ }^{5}$ Entretanto, é provável que essas associações ocorram apenas por acaso. As três condições clínicas que merecem um enfoque mais cuidadoso são discutidas abaixo.

\section{Sindrome nefrótica e glomerulonefrite}

Estão descritos inúmeros casos de associação de síndrome nefrótica com LLC. A lesão histológica corresponde à glomerulonefrite membranosa ou membranoproliferativa, causada pelo depósito de imunoglobulina monoclonal, por vezes crioglobulina, secretada pelas células leucêmicas. A glomerulonefrite entra em remissão com o sucesso do tratamento da LLC., ${ }^{2,7}$

\section{Angioedema adquirido}

$\mathrm{O}$ angioedema adquirido é caracterizado por crises recorrentes de angioedema e dor abdominal, causado por deficiência adquirida do inibidor do primeiro componente do complemento (C1-INH). O tipo I é associado com doença linfoproliferativa incluindo a LLC, enquanto o tipo II é associado com auto-anticorpos. Os dois tipos revelam molécula de C1-INH não funcional devido à atividade da imunoglobulina secretada pelo tumor que causa, ou permite a quebra da molécula do C1-INH tornando-a inativa. Esta síndrome pode ocorrer em pacientes com linfoma esplênico da zona marginal ou de células vilosas. ${ }^{2}$

\section{Doença de pele auto-imune bolhosa}

Embora raro, o pênfigo paraneoplásico é uma doença auto-imune bolhosa da pele associada a tumores linfóides, que em cerca de $30 \%$ dos casos ocorre em associação com a LLC. ${ }^{8}$ Os achados clínicos incluem erosões dolorosas da orofaringe e lábios, conjuntivite pseudomembranosa, lesões 
de pele polimórficas pruriginosas com edema confluente, e pápulas com formação de bolhas centrais nas extremidades ${ }^{2,8}$ Histologicamente é observada acantólise intra-epitelial suprabasilar, necrose de queracinócitos, e alteração vacuolar interfacial. A imunofluorescência revela a presença de anticorpos que reagem com os espaços intracelulares, e depósito de complemento na membrana basal típico de pênfigo bolhoso. $^{2}$

\section{Mecanismos biológicos da auto-imunidade na LLC}

Apesar da importância clínica das alterações imunes associadas à LLC, as causas da produção de auto-anticorpos na LLC ainda não são completamente elucidadas. Estudos com modelos experimentais com animais e com pacientes com AHAI sugerem que a ativação de células $T$ auto-reativas por células apresentadoras de antígeno é um fenômeno fundamental na indução da doença, e que a geração de IgG é dependente de células T.9-13

Existem evidências indicando que células B autoreativas constituem uma parte substancial do total de células $\mathrm{B}$ e que esse conjunto de células B auto-reativas secreta autoanticorpos naturais dirigidos, principalmente, contra epítopos públicos bem conservados. Esse repertório de células B pode, teoricamente, sofrer transformação maligna e, eventualmente, produzir auto-anticorpos. ${ }^{11,12}$

$\mathrm{Na}$ resposta imune, os linfócitos B atuam como células apresentadoras de antígeno profissionais com capacidade de processar e apresentar antígenos, e expressar moléculas co-estimulatórias necessárias para estimular células TH. É descrito que pacientes com AHAI primária a quente, mediada por auto-anticorpos da classe IgG, possuem células TH específicas para proteínas do sistema de grupo sangüíneo Rh que funcionam como auto-antígenos. ${ }^{10}$ Mais recentemente, demonstrou-se que as células B da LLC atuam como células apresentadoras de antígeno aberrantes e são eficientes em processar e apresentar proteína $\mathrm{Rh}$ às células $\mathrm{TH}$ auto-reativas. ${ }^{9}$ Desse modo, um grande número de células $\mathrm{B}$ malignas da LLC presentes no microambiente esplênico entra em contato com altas concentrações de subprodutos de hemácias e plaquetas e apresenta esses antígenos celulares às células TH. ${ }^{9-13}$ A auto-tolerância é mantida, em parte, pela eliminação de linfócitos auto-reativos, mas linfócitos TH específicos para certos auto-antígenos, incluindo a proteína $\mathrm{Rh}$, podem escapar desses mecanismos de controle e, se ativados, podem causar doença auto-imune. ${ }^{9,10}$ Nesse contexto, verificou-se que a expressão da molécula co-estimulatória CD80 presente nos linfócitos B malignos aumenta após contato com linfócitos TH que expressam CD40L. ${ }^{9}$ A Figura 1 esquematiza esse modelo teórico proposto para expli- car a formação de auto-anticorpos em pacientes com LLC.

CTLA-4, um homólogo CD28, atua regulando negativamente a resposta de células $T$, isto é, sua expressão na superfície de células $\mathrm{T}$ ativadas antagoniza sinais de ativação celular e interrompe a resposta de células T. Estudos de polimorfismo do exon 1 do CTLA-4 sugerem que pacientes com AHAI secundária à LLC possuem maior freqüência do alelo G, que tem sido associado com o desenvolvimento de doenças auto-imunes, tais como doença de Graves, tireoidite de Hashimoto, artrite reumatóide, esclerose múltipla, cirrose biliar primária e lupus eritematoso sistêmico. ${ }^{14}$

Estudos do perfil de produção de auto-anticorpos eritrocitários e de citocinas em pacientes com LLC indicam que a auto-imunidade latente na LLC pode estar relacionada à secreção de citocinas tipo Th-2. Análise multivariada revelou que a IL-4 foi significantemente mais elevada, e o IFN- $\gamma$ foi significantemente mais baixo em pacientes com LLC e TAD positivo. ${ }^{15}$

A participação de genes $\mathrm{V}_{\mathrm{H}}$ na fisiopatologia da AHAI secundária à LLC é questionável. Em estudo com apenas 12 indivíduos com AHAI associada à LLC foi verificada a presença de $\mathrm{V}_{1-69}$ em cinco e $\mathrm{V}_{3-33}$ em quatro pacientes, mas em nenhum de 12 indivíduos do grupo controle. ${ }^{16}$ Em contraste, um estudo com quarenta pacientes com AHAI e 166 indivíduos controles detectou que somente sete $(17,5 \%) \mathrm{com}$ AHAI usavam o gene $\mathrm{V}_{1-69}$, e não havia excesso de casos com gene $\mathrm{V}_{3-33}{ }^{.}{ }^{17}$

Alguns autores têm avaliado o impacto do fenômeno da auto-imunidade em LLC sobre o prognóstico da doença. Um estudo observacional sobre a epidemiologia, apresentação clínica e significado das complicações auto-imunes em LLC ou linfoma linfocítico de pequenas células avaliou 132 pacientes durante um período de 12,5 anos. Doze $(9,1 \%)$ 
pacientes apresentaram complicações auto-imunes, sendo que seis $(4,5 \%)$ tiveram AHAI, cinco (3,8\%) PTI, e um $(0,8 \%)$ APSV. Todos os casos de AHAI tiveram TAD positivo para IgG e C3d. Em seis pacientes, o diagnóstico de doença proliferativa foi incidental no momento da apresentação da citopenia auto-imune. A principal causa de morte em pacientes com citopenia auto-imune foi doença maligna secundária. A sobrevivência de pacientes com complicação auto-imune não foi diferente daquela observada em indivíduos sem citopenia auto-imune, porém entre os pacientes com anemia ou trombocitopenia a mortalidade foi significantemente mais elevada naqueles com insuficiência medular. ${ }^{18}$

AHAI também pode ocorrer na LLC devido ao tratamento da leucemia, especialmente com o uso da fludarabina. ${ }^{6}$ A hipótese é que a imunossupressão intensa causada pela doença e pelo tratamento ocasionem diminuição de células T supressoras e perda de auto-tolerância, facilitando a formação de auto-anticorpos que estavam suprimidos. ${ }^{6} \mathrm{Um}$ estudo com 24 pacientes com AHAI após tratamento com fludarabina observou queda do hematócrito entre $8 \%$ e $29 \%$, necessidade de transfusão de hemácias (3 a 36 unidades), e $29 \%$ de óbito. ${ }^{19}$ A análise de 98 casos dessa associação mostrou que a AHAI ocorreu tanto em indivíduos com TAD positivo como em pacientes com TAD negativo antes do tratamento com fludarabina. ${ }^{2}$ A compilação de dados clínicos de vários estudos, que somam 2.777 pacientes, indica que AHAI associada à fludarabina ocorreu em $2 \%$ dos indivíduos após o primeiro tratamento, mas em $20 \%$ dos pacientes que haviam recebido anteriormente vários tipos de tratamento. $^{2}$

A reexposição à fludarabina, cladribina, pentostatina e mesmo a clorambucil pode desencadear um novo episódio de AHAI; portanto, recomenda-se que pacientes com LLC e AHAI não recebam tratamento com análogos da purina.

\section{Tratamento das manifestações auto-imunes da leucemia linfocítica crônica}

Em geral, o tratamento das complicações auto-imunes associadas à LLC é o mesmo que seria empregado caso a doença ocorresse espontaneamente. No entanto, deve ser decidido se a LLC também deve ser tratada, avaliada a possibilidade de que a imunossupressão causada pela LLC ou pelo seu tratamento possa estar causando a auto-imunidade, e considerada a perspectiva de que o tratamento da LLC pode eliminar a complicação auto-imune.

\section{Anemia hemolítica auto-imune}

Não existem estudos controlados para tratamento de AHAI secundária à LLC. É importante enfatizar que a transfusão de hemácias pode ser vital para o paciente uma vez que a hemólise é acentuada, e que a destruição das hemácias transfundidas não é observada como era se imaginava. A reposição com ácido fólico é necessária, e o tratamento específico é similar ao que está estabelecido para a AHAI idiopática.

\section{Corticosteróides}

O tratamento padrão para a hemólise aguda é prednisona ( $1 \mathrm{mg} / \mathrm{kg} / \mathrm{dia}$ ) por 10 a 14 dias. A maioria dos pacientes apresenta boa resposta e a dose é então reduzida lentamente ao longo de três meses. Cerca de $60 \%$ dos pacientes apresentam recidiva do quadro após interrupção da droga e podem receber tratamentos de segunda opção. Os corticosteróides atuam diminuindo: a proliferação de linfócitos, a produção de IL-2, a função de linfócitos T auxiliadores, a função de células NK, a maturação de macrófagos, a quimiotaxia de macrófafos, e a atividade do anticorpo pelo antígeno. Como habitualmente há necessidade de se tratar também a LLC, é necessário evitar o uso de fludarabina, pois a aplicação dessa droga pode desencadear AHAI com quadro clínico muito grave.

\section{Esplenectomia}

O número descrito na literatura de pacientes com AHAI secundária à LLC que foram submetidos à esplectomia é muito pequeno. $\mathrm{O}$ risco cirúrgico em pacientes idosos com imunossupressão é, certamente, maior, porém o uso de esplenectomia por laparoscopia estende a possibilidade de cirurgia para um maior número de pacientes. Em geral, os indivíduos com hemólise causada apenas por anticorpos da classe IgG respondem melhor, e todos os pacientes devem ser previamente vacinados contra pneumococos, meningococos, e haemophilus influenza.

\section{Imunoglobulina endovenosa}

Aproximadamente $40 \%$ dos pacientes com AHAI respondem ao tratamento com $0,4 \mathrm{~g} / \mathrm{kg} /$ dia de imunoglobulina endovenosa por cinco dias, porém a resposta é transitória com duração de três a quatro semanas.

\section{Outros tratamentos}

Os pacientes refratários a corticosteróides podem ser tratados alternativamente com doses padronizadas de ciclosporina, azatioprina, ciclofosfamida ou danazol. A irradiação esplênica pode substituir a esplenectomia em pacientes que tenham contra-indicação cirúrgica, e a plasmaferese pode ser indiciada em pacientes com anticorpos da classe IgM.13

\section{Terapia transfusional}

Transfusões em pacientes com AHAI apresentam um série de problemas potenciais. Como os auto-anticorpos eritrocitários na AHAI são dirigidos contra antígeno comum a praticamente todas as hemácias, o TAD e o teste de 
antiglobulina indireto (TAI, teste de Coombs indireto) são positivos, e todas as unidades de hemácias são incompatíveis com o receptor. Porém, o erro mais comum na orientação terapêutica de pacientes com AHAI é a relutância em transfundi-los devido à incerteza do risco e benefício da transfusão de unidades "incompatíveis" devido à presença do auto-anticorpo. É esperado que reações hemolíticas graves ocorram quando a incompatibilidade é devida a aloanticorpo eritrocitário, porém a experiência clínica indica que quando a incompatibilidade é causada por auto-anticorpo a sobrevivência das hemácias transfundidas é similar à do próprio paciente e pode oferecer um benefício transitório. ${ }^{13,20}$ Portanto, a decisão de transfundir o paciente não é baseada nos testes de compatibilidade, e as indicações para transfusão em pacientes com AHAI são similares àquelas usadas para pacientes anêmicos sem AHAI. $^{20}$

\section{Púrpura trombocitopênica imune}

Devido à raridade dessa complicação não existe tratamento padronizado. O uso de prednisona ( $1 \mathrm{mg} / \mathrm{kg} / \mathrm{dia})$ é indicado em indivíduos com sangramento ativo e/ou contagem plaquetária inferior a $30 \times 10^{9} / \mathrm{L}$. Pacientes refratários devem receber $0,4 \mathrm{~g} / \mathrm{kg} / \mathrm{dia}$ de imunoglobulina endovenosa por cinco dias, metilprednisolona ( $1 \mathrm{~g} /$ dia por três dias), ou serem submetidos à esplenectomia com os cuidados já descritos acima.

\section{Aplasia pura de Série Vermelha}

A aplasia pura de série vermelha associada à LLC deve ser tratada com prednisona ( $1 \mathrm{mg} / \mathrm{kg} / \mathrm{dia})$, e a ciclosporina deve ser adicionada para tratar pacientes refratários ao corticosteróide. Com o aumento do número de reticulócitos duas a três semanas após o início do tratamento, a dose de corticosteróide pode ser reduzida lentamente, mas a ciclosporina deve ser mantida por seis meses e então diminuída gradativamente.

\section{Auto-imunidade após fludarabina}

Conforme mencionado acima, as citopenias desencadeadas pela fludarabina são muito graves e potencialmemente fatais. É muito importante o tratamento de suporte com transfusões de hemácias ou plaquetas, e o uso de antimicrobianos adequados, pois esses pacientes estão profundamente imunossuprimidos e têm grande risco de adquirir infecções bacterianas, fúngicas e/ou virais. Além disso, deve ser instituído o tratamento específico para a citopenia conforme discutido anteriormente. As complicações auto-imunes associadas à fludarabina podem retornar caso o paciente seja tratado novamente com análogos da purina, ou mesmo com clorambucil.

\section{Rituximabe}

Rituximabe, um anticorpo monoclonal quimérico contra o antígeno CD20 presente em linfócitos B, também tem sido usado para tratamento de citopenias auto-imunes. Embora não existam estudos controlados, os resultados de algumas séries que incluem pacientes com AHAI primária e com AHAI secundária sugerem que o rituximabe oferece taxa total de resposta de cerca de $60 \% .^{21}$ A taxa total de resposta para pacientes com PTI primária é ao redor de $80 \% .^{21}$ É descrito que o uso de rituximabe foi benéfico em dois pacientes com aplasia pura de série vermelha associada à LLC. ${ }^{22}$ Embora o tempo de seguimento dos pacientes seja relativamente curto, de até 12 semanas, o tratamento de citopenia auto-imune com rituximabe pode ser uma alternativa para pacientes com doença linfoproliferativa.

Abstract

Chronic lymphocytic leukemia (CLL) is frequently associated with autoimmune diseases directed against hematopoietic cells, including autoimmune hemolytic anemia (AIHA), immune thrombocytopenic purpura (ITP), pure red cell aplasia (PRCA), and immune neutropenia. CLL represents the diagnosis in up to $15 \%$ of the patients with AIHA, and in $50 \%$ of the patients with AIHA secondary to malignancy. ITP occurs in 2\% and PRCA in about $1 \%$ of all CLL patients. Prednisone is the first-line treatment for immune cytopenia related to CLL. About $60 \%$ of patients relapse when treatment is stopped therefore splenectomy, intravenous immunoglobulin, or cyclosporine are reasonable second-line treatments. Although the data on pathophysiology are very limited, it appears that the autoimmune mechanisms are related to the activity of the leukemic B lymphocytes that act as aberrant antigen-presenting cells, and are effective in processing and presenting proteins derived from red cells or platelets to autoreactive TH cells. TH cells specific for certain auto-antigens escape from control mechanisms and when activated may initiate auto-immune disease. Patients with AIHA secondary to CLL should not receive fludarabine because there is an increased frequency of severe and fatal AIHA in patients treated with purine nucleoside analogues. Patients who are more immunosuppressed due to several previous treatments are at higher risk for developing this autoimmune complication. Rev. bras. hematol. hemoter. 2005;27(4): 257-262.

Key words: Chronic lymphocytic leukemia; autoimmune hemolytic anemia; blood transfusion; immune thrombocytopenic purpura; pure red cell aplasia.

\section{Referências Bibliográficas}

1. Berlin R. Red cell survival studies in normal and leukaemic subjects; latent haemolytic syndrome in leukaemia with splenomegaly - nature of anaemia on leukaemia - effect of splenomegaly. Acta Med Scand 1951;139(suppl 252):1-141.

2. Hamblin T. Autoimmune disease and its management in chronic lymphocytic leukemia. In: Chronic Lymphoid Leukemias. Ed. Cheson BC, 2nd ed., 2001, pp. 435-458. 
3. Engelfriet CP, Overbeeke MAM, von dem Borne AEGK. Autoimmune hemolytic anemia. Semin Hematol 1992;29:3-12.

4. Hamblin TJ, Oscier DG, Young BJ. Autoimmunity in chronic lymphocytic leukaemia. J Clin Pathol 1986;39:713-716.

5. Dührsen U, Augener W, Zwingers T et al. Spectrum and frequency of autoimmune derangements in lymphoproliferative disorders: analysis of 637 cases and comparison with myeloproliferative diseases. Br J Haematol 1987;67:235-239.

6. Diehl LF, Ketchum LH. Autoimmune disease and chronic lymphocytic leukemia: autoimmune hemolytic anemia, pure red cell aplasia and autoimmune thrombocytopenia. Sem Hematol 1998;25:80-97.

7. Moulin B, Ronco PM, Mougenot B et al. Glomerulonephritis in chronic lymphocytic leukaemia and related B cell lymphomas. Kidney Int 1992;42:127-135.

8. Rodot S, Botcazou V, Lacour JP et al. Paraneoplastic pemphigus: review of the literature, apropos of a case associated with chronic lymphocytic leukemia. Rev Med Interne 1995;16:938-943.

9. Hall AM, Vickers MA, McLeod E et al. Rh autoantigen presentation to helper cells in chronic lymphocytic leukemia by malignant cells. Blood 2005; $105: 2.007-2.015$

10. Barker RN, Hall AM, Standen GR et al. Identification of T-cell epitopes on the Rhesus polypeptides in autoimmune hemolytic anemia. Blood 1997;90:2.701-2.715.

11. Caligaris-Cappio F. Biology of chronic lymphocytic leukemia. Rev Clin Exp Hematol 2000;4:5-21.

12. Pritsch O, Maloum K, Dighiero G. Basic biology of autoimmune phenomena in chronic lymphocytic leukemia. Semin Oncol 1998;2 5: 34-41.

13. Diehl LF, Ketchum LH. Autoimmune disease and chronic lymphocytic leukemia: autoimmune hemolytic anemia, pure red cell aplasia and autoimmune thrombocytopenia. Semin Oncol 1998;25:80-97.

14. Pavkovic M, Georgievski B, Cevreska L et al. CTLA-4 exon 1 polymorphism in patients with autoimmune blood disorders. Am J Hematol 2003;72:147-149.
15. Barcellini W, Montesano R, Clerici G et al. In vitro production of anti$\mathrm{RBC}$ antibodies and cytokines in chronic lymphocytic leukemia. Am J Hematol 2002;71:177-183.

16. Efremov DG, Ivanovski M, Siljanovski $\mathrm{N}$ et al. Restricted immunoglobulin VH region repertoire in chronic lymphocytic leukemia patients with autoimmune hemolytic anemia. Blood 1996;87:3.869-3.876.

17. Hamblin TJ, Davies Z, Oscier D et al. In chronic lymphocytic leukemia (CLL) autoimmune haemolytic anemia (AIHA) is not related to any particular immunoglobulin V gene usage. Br J Haematol 1999;105 (suppl):88.

18. Kyasa MJ, Parrish RS, Schichman SA et al. Autoimmune cytopenia does not predict poor prognosis in chronic lymphocytic leukemia/small lymphocytic lymphoma. Am J Hematol 2003;74:1-8.

19. Weiss R, Freiman J, Kweder SL et al. Hemolytic anemia after fludarabine therapy for chronic lymphocytic leukemia. J Clin Oncol 1998;16:1.8851.889 .

20. Petz LD. A physician's guide to transfusion in autoimmune haemolytic anaemia. Br J Haematol 2004;124:712-716.

21. Narat S, Gandla J, Hoffbrand AV et al. Rituximab in the treatment of refractory autoimmune cytopenias in adults. Haematologica 2005;90: $1.273-1.274$

22. Ghazal H. Successful treatment of pure red cell aplasia with rituximab in patients with chronic lymphocytic leukemia. Blood 2002;99:1 .092-4.

Avaliação: Carlos Sergio Chiattone

(publicado após acordo do Editor)

Conflito de interesse: Artigo derivado do II Encontro Brasileiro de

Consenso da LLC

Recebido: $05 / 11 / 2005$

Aceito: 15/11/2005 